\title{
Mujer, alegoría e imperio en el drama de Miguel de Cervantes El cerco de Numancia
}

\author{
VERÓNICA RYJIK*
}

La relación entre los eventos retratados en el drama de Miguel de Cervantes $E l$ cerco de Numancia y las circunstancias político-militares del reinado de Felipe II ha sido puesta de relieve por diversos estudios críticos. Sin embargo, la cuestión de las implicaciones ideológicas de esta relación ha generado toda una polémica en los últimos cincuenta años. Por un lado, la interpretación tradicional, que se apoya sobre todo en el discurso profético del río Duero al final de la primera jornada, tiende a considerar la obra como una expresión de patriotismo profundo y una apología de la gloria imperial de España. Por ejemplo, Ricardo Doménech en su edición del drama de 1967 escribe: "El autor encontró en Numancia un pretexto -esto sí, un excelente pretexto- para hablar a los españoles de su tiempo de la grandeza española que estaban viviendo y protagonizando"1. De un modo parecido, Juan Bautista Avalle-Arce subraya la importancia del motivo de renovatio imperii en la obra y afirma que "el nacionalismo español, formado al socaire de la idea imperial, informa y explica por igual los versos de La Numancia, las doctrinas lingüísticas de Fernando de Herrera, o el cambio en la denominación del idioma, de castellano a español"2. En un estudio más reciente Francisco Vivar analiza la función del ideal pro patria mori en la Numancia y concluye que la obra refleja el optimismo imperial español de 1580, al ver a los españoles como herederos de los numantinos y el futuro imperial como un designio divino ${ }^{3}$. Conviene señalar que el subtexto

* Franklin \& Marshall College, U.S.A.

1. "Introducción”, La destrucción de Numancia, ed. Ricardo Doménech, Madrid, Taurus, 1967, p. 14.

2. Nuevos deslindes cervantinos, Barcelona, Ariel, 1975, p. 275n.

3. "El ideal pro patria mori en La Numancia de Cervantes", Cervantes, 20.2, 2000, p. 28. Véase 
cristiano de la Numancia constituye uno de los argumentos utilizados con frecuencia para demostrar el nacionalismo militante del primer Cervantes. Así, para Joaquín Casalduero, el sentido principal de la obra reside en la cristianización del concepto pagano de la fama, por lo cual "el valor de los numantinos vencidos es una prefiguración en el sentido cristiano del valor de la España vencedora de Cervantes"4. También Robert Marrast afirma que el nacionalismo del drama se apoya en la afirmación de la superioridad del futuro imperio español sobre el romano, debido a su papel de defensor de la causa católica: "España triunfará cuando la causa que defienda sea la de Dios, cuando sus soldados combatan por una causa santa: contra los moriscos de las Alpujarras, contra los herejes de Flandes, contra los secuaces de Mahoma"5. Siguiendo la misma línea de investigación, William Whitby estudia el sacrificio como el tema central de la Numancia, mientras que Brien Stiegler analiza los motivos apocalípticos en la obra y sugiere que Cervantes crea un paralelo entre la imagen del reinado de Felipe II y la Edad Dorada al final de los tiempos ${ }^{6}$.

también VIVAR, La Numancia de Cervantes y la memoria de un mito, Madrid, Biblioteca Nueva, 2004; CASAlduero, Joaquín, Sentido y forma del teatro de Cervantes, Madrid, Aguilar, 1951; AuB, Max, "La Numancia de Cervantes", La Torre, 4, 1956, pp. 99-111; CoRrEA, Gustavo, "El concepto de la fama en el teatro de Cervantes", Hispanic Review, 27, 1959, pp. 280-302; MARRAST, Robert, "Introducción", El cerco de Numancia, Miguel de Cervantes Saavedra, ed. Robert Marrast, Salamanca, Anaya, 1961, pp. 5-25; Selig, Karl-Ludwig, "La Numancia: a Reconsideration of the Duero Speech", Homenaje a William L. Fichter: estudios sobre el teatro antiguo hispánico y otros ensayos, ed. A. D. Kossoff y J. Amor y Vázquez, Madrid, Castalia, 1971, pp. 681-685; Belli, Ángela, "Cervantes' El cerco de Numancia and Euripides' The Trojan Women”, Kentucky Romance Quarterly, 25, 1978, pp. 121-128; García Martín, Manuel, Cervantes y la comedia española en el siglo XVII, Filosofía y Letras 117, Salamanca, Ediciones Universidad de Salamanca, 1980; LEWIS-SMITH, Paul, "Cervantes' Numancia as Tragedy and as Tragycomedy", Bulletin of Hispanic Studies, 64.1, 1987, pp. 15-26; ZIMIC, Stanislav, El teatro de Cervantes, Madrid, Castalia, 1992; Sevilla Arroyo, F. y A. Rey Hazas, "Introducción", Obra completa, Miguel de Cervantes Saavedra, ed. F. Sevilla Arroyo y A. Rey Hazas, I. Alcalá de Henares, Centro de Estudios Cervantinos, 1993, pp. xi-xciii; STIEGLER, Brian N., "The Coming of the New Jerusalem: Apocalyptic Vision in Cervantes' La Numancia", Neophilologus, 80.4, 1996, pp. 569581; WeINER, Jack, "La Numancia de Cervantes y la alianza entre Dios e Israel”, Neophilologus, 81.1, 1997, pp. 63-70.

4. Sentido y forma, p. 297.

5. "Introducción", p. 20.

6. Whitвy, William M., "The Sacrifice Theme in Cervantes' Numancia”, Hispania, 45.2, 1962, pp. 205-210; STIEGLER, "The Coming of the New Jerusalem", pp. 569-581. También se deben mencionar los estudios de STRoud, Matthew D., "La Numancia como auto secular", Cervantes: su obra y su mundo, ed. Manuel Criado del Val, Madrid, EDI-6, 1981, pp. 303-307; ZIMIC, El teatro de Cervantes; SchmidT, Rachel, "The Development of Hispanitas in Spanish Sixteenth-Century Versions of the Fall of Numancia", Renaissance and Reformation, 19.2, 1995, pp. 27-45; WeINER, "La Numancia de Cervantes"; VIVAR, "El ideal pro patria mori" y La Numancia de Cervantes. Existe al mismo tiempo una tendencia crítica que rechaza el mensaje cristiano del drama cervantino, al enfocarse en el paganismo de los numantinos, que se expresa a través de los ritos en la segunda jornada y culmina en su elección del suicidio colectivo como la única solución posible. Como observa Frederick A. DE ARMAS, "it would be difficult, then, to see suicide as an event that would inspire catharsis in a religious audience of Cervantes's time", "The Necromancy of Imitation: Lucan and Cervantes's La Numancia”, El arte nuevo de estudiar comedias: Literary Theory and Spanish Golden Age Drama, ed. Barbara Simerka, Lewsiburg, Bucknell University Press, 1996, p. 253. Véase también LAFFRANQUE, Marie, "De l'histoire au mythe: A propos du 'siège de Numance' de Cervantès", Revue Philosophique de la Fran- 
Por otro lado, en los últimos 25 años han aparecido varias interpretaciones alternativas del drama cervantino, que parten de los significativos paralelismos entre el imperio romano de la obra y el imperio español de la época de Cervantes $^{7}$. Alfredo Hermenegildo cree ver en la obra una posible alusión a la sublevación de los moriscos de Alpujarras y su dura represión por Don Juan de Austria $^{8}$. Para Vicente Gaos, la Numancia no es imperialista, sino una obra "esquiva y ambigua donde las haya. Merced a una sutil transposición de tiempos históricos, a la simbiosis romanos-españoles, Cervantes deja a los espectadores sin saber a qué carta quedarse"9. Willard King señala que la España gloriosa del final de la profecía de Duero, envidiada y temida por miles de naciones e involucrada en una constante guerra, refleja la Roma militante y agresiva de Escipión. Así pues, situada dentro del contexto de la polémica sobre la legitimidad de la política imperialista de la monarquía española en el Nuevo Mundo y en Flandes, la Numancia ya no se puede ver como un mero canto propagandísti$\mathrm{co}^{10}$. De la misma manera, Caroll Jonson observa que la semejanza entre la actuación de los romanos en la obra y la de los españoles en Flandes a finales del siglo XVI apunta a un doble mensaje ideológico: la exaltación patriótica por un lado y la crítica de la política exterior de Felipe II por el otro ${ }^{11}$. Finalmente, uno de los críticos que ha apoyado esta perspectiva con más consistencia es Frede-

ce et de l'Étranger, 157, 1967, p. 290; GAOs, Vicente, Cervantes: novelista, dramaturgo, poeta, Barcelona, Planeta, 1979, pp. 140-143; MANDEL, Adrienne Schizzano, "La Numancia: cuando el último hombre ha dicho su palabra”, Cervantes: su obra y su mundo, ed. Manuel Criado del Val, Madrid, EDI6, 1981, p. 321; LARSEN, Kevin S., "Observations on the Animals and Animal imagery in Cervantes' Theater", Modern Language Studies, 14.4, 1984, p. 71; MAGLIONE, Sabatino G., "Amity and Enmity in Cervantes's La Numancia", Hispania, 83.2, 2000, pp. 186-187; MCKendRICK, Melveena, "Writings for the Stage", The Cambridge Companion to Cervantes, ed. Anthony J. Cascardi, Cambridge, Cambridge University Press, 2002, p. 137.

7. El hecho de que los españoles del siglo XVI se encuentran en la posición que en la Numancia corresponde a los romanos ya fue destacado por CASALDUERO: "A finales del primer Barroco, en la época en que Cervantes escribe la Numancia, los españoles eran los que sitiaban, no los sitiados, y por dos veces, como él mismo se complace en recordarlo, habían tenido a Roma bajo su poder," Sentido y forma, p. 297. Véase también DOMÉNECH, "Introducción", p. 23; LAFFRANQUE, "De 1'histoire au mythe", p. 284; HeRmenegildo, Alfredo, La "Numancia" de Cervantes, Biblioteca de Crítica Literaria 1. Madrid, BCL, 1976, p. 53; CAnAvaggio, Jean, Cervantes, trad. J. R. Jones, New York, W.W. Norton \& Company, 1990, p. 124; SCHMIDT, "The Development of Hispanitas", p. 41. Por otro lado, Stanislav ZIMIC rechaza cualquier conexión entre la Roma de Escipión y el imperio español: "Ya ninguna actitud, ninguna aspiración esencial de la España imperial la une al antiguo Imperio romano", El teatro de Cervantes, p. 85.

8. La "Numancia" de Cervantes, pp. 47-51.

9. Cervantes, p. 146. GaOs considera las profecías sobre la futura grandeza de España una expresión del relativismo histórico: si ayer la hegemonía fue de los romanos, hoy lo es de los españoles y mañana será de cualquier otro pueblo, ibid., p. 135. Marie LAFFRANQUE expresa una opinión parecida: "En même temps qu' au naufrage de la force numantine, précédent celui de Rome, comment ne pas songer ici au déclin déjà sensible de la puissance espagnole," "De l'histoire au mythe", p. 289.

10. “Cervantes' Numancia and Imperial Spain”, MLN, 94, 1979, pp. 200-221.

11. "La Numancia y la estructura de la ambigüedad cervantina", Cervantes: su obra y su mundo, ed. Manuel Criado del Val, Madrid, EDI-6, 1981, pp. 309-16. Esta perspectiva del doble mensaje ha sido adoptada por varios críticos modernos. Por ejemplo, Sabatino MAGLIONE estudia los motivos de la enemistad y la venganza en el drama y concluye que Cervantes consigue de una manera sutil tanto celebrar como criticar la noción del imperio: 
rick de Armas, quien explora las afinidades entre la Numancia y el mundo de la Antigüedad clásica, algo que le permite enfatizar ciertas contradicciones y complejidades del texto cervantino, que invitan a múltiples lecturas ${ }^{12}$.

Como demuestra este breve repaso de los diversos acercamientos críticos a El cerco de Numancia, estamos lejos de llegar a algún tipo de consenso en lo que respecta al mensaje político de la obra. Es obvio que hoy día resulta prácticamente imposible especular acerca de los objetivos de Cervantes en el momento de escribir su tragedia y, por lo tanto, podemos afirmar con Georges Güntert que "a los que siguen interrogándose sobre las 'verdaderas' intenciones del autor cabe decirles de una vez por todas que nunca se podrán descubrir aquéllas"13. Al mismo tiempo, es difícil aceptar cualquier lectura unidimensional de esta obra que ha dado lugar a una multitud de interpretaciones distintas y a menudo contradictorias, algo que no nos puede sorprender en un autor tan polifacético y ambiguo como Cervantes ${ }^{14}$. Es cierto que muchos han

The Numantians' mass suicide... is not only an act of sacrificial friendship and patriotism, but also an act of vengeance which calls on the Spaniards of the future to avenge the injuries they suffered under the cruel Roman regime. The informed audience may question whether the sixteenth-century Spanish avengers governed their subjugated peoples with more clemency and tolerance than the Romans treated the Numantians. "Amity and Enmity", p. 186.

Véase también Canavaggio, Cervantes, pp. 123-124, Schmidt, "The Development of Hispanitas", p. 41 y MCKENDRICK, "Writings for the Stage", pp. 136-137.


mancia”, Neophilologus, 58, 1974, pp. 34-40; “Achilles and Odysseus: An Epic Contest in Cervantes' La Numancia”, Cervantes: estudios en la víspera de su centenario, Teatro del Siglo de Oro, Estudios de Literatura 25. II. Kassel, Reichenberger, 1994, pp. 357-370; "Painting and Graffiti: (Sub)Versions of History in Golden Age Theater (Notes on Cervantes and Claramonte)", Gestos, 11.21, 1996, pp. 83101; Cervantes, Raphael and the Classics, Cambridge, Cambridge University Press, 1998; "Numancia as Ganymede: Conquest and Continence in Giulio Romano, Cervantes, and Rojas Zorrilla", Echoes and Inscriptions: Comparative Approaches to Early Modern Spanish Literatures, ed. B. Simerka y C. Weimer, Lewisburg, Bucknell University Press, 2000, pp. 250-270. También es importante señalar los trabajos de Michael ARMSTRONG-Roche, "Imperial Theater of War: Republican Virtues Under Siege in Cervantes's Numancia", Journal of Spanish Cultural Studies, 6.2, 2005, pp. 185-203; Eric C. GrAF, "Valladolid dellenda est: La política teológica de La Numancia", Theatralia, 5, 2003, pp. 27382; y Barbara SIMERKA, quien estudia la indeterminación genérica del drama como un factor que contribuye sumamente al escrutinio polifónico del imperialismo, Discourses of Empire: Counter-Epic Literature in Early Modern Spain, University Park, The Pennsylvania State University Press, 2003, pp. 15-128. Finalmente, en un artículo reciente Aaron KAHN sitúa la Numancia dentro de toda una serie de obras dramáticas escritas a lo largo de la segunda mitad del siglo XVI que parecen censurar la política exterior de Felipe II, "Moral Opposition to Philip in Pre-Lopean Drama", Hispanic Review, 74.3, 2006, pp. 227-250.

13. "Arte y furor en La Numancia", Actas del VIII congreso de la Asociación Internacional de Hispanistas, 22-27 agosto 1983, Brown University, Providence, RI, ed. A. D. Kossoff, J. Amor y Vázquez, R. H. Kossoff y G. Ribbans. I. Madrid, Ediciones Istmo, 1986, p. 672.

14. GÜNTERT, si bien no comparte la opinión de críticos como Hermenegildo, admite que "el hecho de que algunos estudiosos y dramaturgos vayan más allá y sostengan que el discurso nacionalista de las figuras alegóricas no es sincero, confirma el ambiguo carácter de La Numancia," "La tragedia como lugar privilegiado de la reflexión metapoética: La Numancia”, Theatralia, 5, 2003, p. 272. Además, conviene recordar que incluso las representaciones de la Numancia han servido a fines bien diferentes. Si en 1808 la Numancia se representa en Zaragoza para alentar el sentimiento de independencia ante la invasión napoleónica, siete años más tarde, la versión de Ignacio López de Ayala se estrena como señal de protesta en contra del absolutismo de Fernando VII. En 1937 la adaptación de Ra- 
defendido el optimismo de la Numancia apoyándose en el hecho de que es una obra relativamente temprana. Según Doménech, por ejemplo, "este Miguel de Cervantes de 1580, no sólo dista mucho del Miguel de Cervantes desilusionado y escéptico de El Quijote, sino que es en cierto modo su antípoda"15. Creo, sin embargo, que puede ser un poco peligroso hacer una clara separación en la producción cervantina entre un 'antes' y un 'después', que no se relacionan de ninguna manera ${ }^{16}$. Además, en el momento de escribir su tragedia Cervantes ya tiene unos 35 años y no puede ser comparable a un joven Lope de Vega que por la misma época escribe Los hechos de Garcilaso de la Vega, una comedia que dista considerablemente de su obra posterior en forma y madurez. Por lo tanto, coincido con los críticos como Melveena McKendrick que encuentran en la Numancia la polivalencia que caracteriza toda la escritura cervantina: "What we have here is an unexpected glimpse of the perspectivism and provisionalism of the Quijote. The contrasting points of view are external as well as internal to the play-text. Within the text Scipio and the Numantians, as well as the men and the women, see the situation in different ways, and we ourselves take the force of that polyvalence..." ${ }^{17}$. Ahora bien, si aceptamos que la Numancia invita en efecto a diferentes lecturas y que su texto, aparte de una exaltación patriótica, contiene una perspectiva crítica del imperio español, surge una pregunta lógica: ¿cuál es la imagen de la nación propagada por Cervantes como alternativa al imperialismo militante? Creo que un análisis de la interacción de los diferentes niveles de la obra nos puede ayudar a delinear algunas posibles respuestas a esta pregunta.

En su edición del drama Hermenegildo observa que la ordenación de los personajes se realiza en tres planos: individual, general y moral o alegórico ${ }^{18}$.

fael Alberti inspira a los defensores republicanos de Madrid, mientras que en 1956 la misma pieza sirve para confirmar las convicciones nacionalistas de los franquistas. Véase GAos, Cervantes, pp. 146-147, GÜNTERT, "Arte y furor", p. 671.

15. "Introducción", p. 7. Aparte de la juventud del escritor, se ha insistido en el hecho de que Cervantes escribe la Numancia en el momento de mayor auge de la realidad imperial. Por ejemplo, según DOMÉNECH, "el Miguel de Cervantes de 1580, creía profundamente en el imperio español y en los valores generales que éste defendía en el mundo, y por los cuales él mismo había luchado como soldado y había sido malherido", ibid., p. 36. Jack WEINER también señala que Cervantes de la Numancia sólo ha conocido la España invencible y, por lo tanto, rechaza la posibilidad de una crítica del imperialismo español en la obra: "Con todas estas victorias Cervantes habría creído que efectivamente España llevaba la palabra de Dios por todo el mundo y que España hacía así justicia obedeciendo los mandamientos de Dios", “La Numancia de Cervantes", p. 68. A este acercamiento se oponen los autores ya citados que creen ver en la Numancia una crítica de la política agresiva que la monarquía española ha usado para llegar a este auge y mantener su hegemonía.

16. Para WeInER, el momento decisivo podría ser 1588, el año de la pérdida de la Armada Invencible, "La Numancia de Cervantes", p. 69.

17. "Writings for the Stage", p. 137. La relación entre la Numancia y el Quijote ha sido puesta de relieve por varios investigadores pero el que más ha insistido en la imposibilidad de separar la tragedia de la obra posterior cervantina es GAOs: "Cervantes era ya en 1580 Cervantes, aunque aun no hubiera alcanzado toda su madurez humana ni su plenaria personalidad de escritor dotado de genial expresión”, Cervantes, p. 147. Véase también KING, "Cervantes' Numancia”, p. 217.

18. "Introducción”, El cerco de Numancia, Miguel de Cervantes Saavedra, ed. Alfredo Hermenegildo, Madrid, Castalia, 1994, pp. 27-28. 
Para los objetivos de esta investigación propongo reducir esta clasificación a dos planos: el plano real de los numantinos y los romanos y el plano simbólico de los personajes alegóricos. Varios críticos han notado que los personajes alegóricos (o las figuras morales), como España, Duero, la Guerra, etc., tienen una función semejante a la de los coros de la tragedia griega, que es comentar el sentido de la acción y amplificar, generalizar los casos más aislados, representados por los personajes nominados e innominados ${ }^{19}$. Mediante estas generalizaciones a lo largo de la obra se establece un vínculo entre el heroísmo numantino y las futuras glorias de la España imperial. Como señala Carmen Peraita, "a través de las figuras alegóricas el tiempo de Numancia coexiste con la circunstancia histórica del propio espectador quinientista" ${ }^{20}$. En otras palabras, es en el discurso de las figuras morales donde más claramente se sugieren los paralelos entre la agresión de la antigua Roma y la de la España del siglo XVI. A este plano alegórico se contrapone el plano real de la ciudad sitiada, cuyos habitantes encarnan lo que parece ser la imagen del español ideal para Cervantes ${ }^{21}$. Aunque los personajes alegóricos nunca intervienen en el desarrollo de la trama protagonizada por los romanos y los numantinos, coincido con Hermenegildo en que estos dos planos no se pueden considerar aisladamente, como veremos en seguida ${ }^{22}$.

Vivar señala que, desde el principio de la obra, existe una fuerte asociación entre los numantinos y su tierra: "El lugar tiene una importancia esencial, debido a la relación de equivalencia que se establece entre la ciudad y los numantinos"23. Por consiguiente, el ataque físico a la tierra de Numancia por parte de los romanos simboliza un ataque en contra de sus habitantes. Esta asociación, no obstante, resulta algo más compleja, gracias a la interacción entre el plano real y el alegórico, como intentaré demostrar. La aparición del personaje de España establece un vínculo entre la tierra numantina y la tierra española mediante el uso de la metáfora corporal. España habla de sus "flacos miembros abrasados" 24 por los diferentes invasores extranjeros y de las "mil cruezas" 25 que ejercen en ella los bárbaros romanos. Es decir, al excavar la tie-

19. Canavaggio, Cervantès dramaturge: un théâtre à naître, Paris, Presses Universitaires de France, 1977, p. 347; Friedman, Edward H., The Unifying Concept: Approaches to the Structure of Cervantes' Comedias, York, SC, Spanish Literature Publications Company, 1981, p. 50; HERMENEGILDO, "Introducción", p. 36.

20. "Idea de la historia y providencialismo en Cervantes: Las profecías numantinas", Actas del II Congreso Internacional de la Asociación de Cervantistas. Nápoles, 4-9 de abril de 1994, ed. Giuseppe Grilli, Nápoles, Instituto Universitario Orientale, 1995, p. 150.

21. Cory A. REED nota que "the audience first recognizes the tragic sacrifice and noble legacy of Numancia, and then it must reaffirm the shared values of an idealized national identity in order to consider whether modern Spain has conducted its political responsibilities in accordance with those values", "Identity Formation and Collective Anagnorisis in Numancia", Theatralia, 5, 2003, p. 73.

22. Hermenegildo, "Introducción”, p. 28.

23. "El ideal pro patria mori", p. 8.

24. Cervantes SaAvedra, Miguel de, El cerco de Numancia, ed. Alfredo Hermenegildo, Madrid, Castalia, 1994, 1.362.

25. Ibid., 1.384 . 
rra numantina, los hombres de Escipión están violentando el cuerpo de España. Cabe enfatizar el hecho de que se trata de un cuerpo femenino, puesto que la figura de la "sola y desdichada" España aparece caracterizada como mater dolorosa, quien se queja de sus agravios y del sufrimiento de sus hijos ante una figura masculina, el río Duero ${ }^{26}$. También es importante notar que, en sus quejas, España introduce el tema principal de la obra, la libertad:

¿Será posible que contino sea

esclava de naciones extranjeras

y que un pequeño tiempo yo no vea

de libertad tendidas mis banderas ${ }^{27}$

Curiosamente, todos estos motivos (la queja femenina, la agresión extranjera, encarnada por la violación física, la dualidad esclavitud / libertad y la preocupación por el destino de los hijos) reaparecen más tarde en el plano real del drama, cuando las mujeres numantinas advierten a sus hombres del peligro de dejarlas en el poder de los romanos:

¿Queréis dejar, por ventura,

a la romana arrogancia

las vírgenes de Numancia

para mayor desventura?

$\mathrm{Y}$ a los libres hijos vuestros

queréis esclavos dejallos? ${ }^{28}$

Así pues, aparte de la conexión los numantinos-Numancia-España, se establece otra identificación más específica: las mujeres de Numancia-España, que se acentúa por la aparición al final de la tercera jornada de un personaje innominado: la Madre que llora el sufrimiento de sus hijos hambrientos ${ }^{29}$. Ahora, esta identificación bastante obvia (y en realidad poco sorprendente) adquiere un sentido interesante si analizamos el papel que desempeñan en la Numancia los personajes femeninos. Para ello, no obstante, primero tenemos que dirigir nuestra atención a los hombres y, en concreto, a la manera en que

26. Peraita, "Idea de la historia", p. 147. De Armas sitúa la imaginería sexual asociada en la tragedia con Numancia dentro de la tradición clásica de comparar el cerco de una ciudad o fortificación con la conquista amorosa de una mujer. Así, por ejemplo, el caballo troyano puede verse como una representación fálica de la victoria sobre una mujer resistente, "Numancia as Ganymede", p. 259.

27. Cervantes, El cerco de Numancia, 1.369-72.

28. Ibid., 3.1310-15. Otro motivo que comparten el discurso de España con el de las mujeres numantinas es el honor. Como nota SCHMIDT, "the conflation of national honor with personal honor manifested in the figure of Spain as a violated woman represents the merging of individual with communal interests, the conflict at the base of sixteenth-century Spanish accounts of Scipio's siege of Numancia", "The Development of Hispanitas", pp. 40-41. Para la investigadora, el problema del honor, expresado por las mujeres, serviría como justificación del suicidio colectivo en los ojos del público de la época, ibid., p. 41.

29. Conviene señalar que estructuralmente es una aparición perfectamente simétrica, puesto que las quejas de la madre España por el dolor de sus hijos numantinos se sitúan al final de la primera jornada. 
los dos bandos pasan de pasividad a acción y viceversa. Se puede decir que esta oposición acción / inacción subyace la estructura de todo el drama y, hasta cierto punto, asegura su unidad ${ }^{30}$. En este sentido resultan de suma importancia unas palabras que Escipión pronuncia en su arenga inicial y que, en mi opinión, establecen la pauta para el resto de la obra:

Cada cual se fabrica su destino.

No tiene allí fortuna alguna parte.

La pereza fortuna baja cría;

la diligencia, imperio y monarquía ${ }^{31}$.

Así pues, desde el principio se pone mucho énfasis en la diligencia, en fabricar, hacer, obrar, actuar, etc. y, como intentaré demostrar, este motivo es crucial para el desarrollo de la obra.

Al principio de la primera jornada el ejército romano se encuentra en una etapa de estatismo, algo que provoca un comentario sarcástico de Escipión:

mas no hay que reprimir, a lo que veo,

la furia del ejército presente,

que olvidado de gloria y de trofeo,

yace embebido en la lascivia ardiente ${ }^{32}$.

Es al menos curioso que desde el primer momento la inacción de los romanos esté relacionada con la lujuria y, por consiguiente, con las mujeres. Para reforzar esta idea, Escipión ubica la causa del deterioro de sus tropas en el hecho de que "la blanda Venus con el duro Marte / jamás hacen durable ayuntamiento" 33 . En un discurso vehemente, el general acusa a sus soldados de ser unos afeminados, nota sus delicadas manos y lustrosos rostros y dice que están "vencidos / del bajo antojo y femenil, liviano"34. No es sorprendente, por lo tanto, que su primer paso hacia la reforma del ejército sea desterrar a las prostitutas del campamento:

\footnotetext{
De nuestro campo quiero, en todo caso, que salgan las infames meretrices, que de ser reducidos a este paso, ellas solas han sido las raíces ${ }^{35}$.
}

En resumen, la inmovilidad (y podemos decir, la impotencia) de los romanos al principio de la obra parece provocada por la presencia de las mujeres

30. Para un análisis de la estructura de la Numancia véanse los estudios de CASALDUERo, Sentido y forma, EDWARDS, Gwynne, "La estructura de Numancia y el desarrollo de su ambiente trágico", Cervantes: su obra y su mundo, ed. Manuel Criado del Val, Madrid, EDI-6, 1981, pp. 293-301, y FRIEDMAN, The Unifying Concept.

31. Cervantes, El cerco de Numancia, 1.157-60.

32. Ibid., 1.17-20.

33. Ibid., 1.89-90.

34. Ibid., 1.121-22.

35. Ibid., 1.129-32. 
que funcionan como un elemento corrosivo. Esta inmovilidad calificada por Escipión como "pereza" es contrastada por el dinamismo de los numantinos, quienes "a nuestro pesar, con arrogancia... defienden este nido de Numancia"36. Como solución, el general romano propone un plan de acción inhabitual, que él mismo llama "mi nueva traza"37. En vez del combate, elige la táctica del cerco, es decir, decide que no dejará actuar a los numantinos: "yo pienso hacer que el numantino / nunca a las manos con nosotros venga"38. Al mismo tiempo, obliga a sus propios soldados a salir de la inercia y empezar a actuar, aunque sea sólo para "romper y cavar la dura tierra"39. A pesar de que la táctica astuta de Escipión provoca el desprecio de sus enemigos, el general consigue que, para el principio de la segunda jornada, los papeles se inviertan y ahora sean los numantinos quienes, aunque forzadamente, están "privados / de ejercitar sus fuertes brazos" 40 . El paralelo entre el ambiente de apatía en el ejército romano a principios de la primera jornada y la pasividad impuesta a los numantinos sitiados a principios de la segunda es reforzado por la asociación entre la inacción y la feminización: "pues en tales términos nos vemos, / que estamos como damas encerrados"41. Además, reaparece la referencia a la presencia de Venus pero dentro de un contexto algo diferente. En un discurso que se hace eco de las palabras de Escipión, Leonicio reprueba a su mejor amigo Marandro por estar pensando en amores en tiempos de guerra:

Al tiempo que del dios Marte
has de pedir el favor,
¿te entretienes con amor,
quien mil blanduras reparte? ${ }^{42}$

36. Ibid., 1.114-16.

37. Ibid., 1.348 .

38. Ibid., 1.313-14.

39. Ibid., 1.326 .

40. Ibid., 1.413-14. El sentido de impotencia, provocado por esta pasividad, como móvil de la acción para los numantinos ha sido comentado por algunos críticos. Jesús MAESTRO, por ejemplo, escribe: La Numancia constituye, en este sentido, un análisis de las posibilidades del ejercicio de la libertad humana en circunstancias extremas de impotencia, individual y colectiva, para su desarrollo, es decir, de incapacidad para actuar en libertad, al carecer el sujeto completamente de facultades de poder (posibilidad), en una situación en la que, de forma muy dramática, el ser humano sigue conservando exacerbadamente tanto el deseo de acción (voluntad) como las capacidades de conocimiento y reflexión (saber) necesarias para actuar. La Numancia es en este sentido la expresión trágica de una impotencia humana suprema, ante todo consciente de sí misma, y que con toda la fuerza de su voluntad se enfrenta a una realidad superior e inderogable, de naturaleza igualmente humana, que ha de negar en el adversario, hasta destruirla absolutamente, toda posibilidad de vida. La escena imaginaria: poética del teatro de Miguel de Cervantes, Madrid, Iberoamericana, 2000, pp. 156-157.

Véase también BelLI, "Cervantes' El cerco de Numancia”, p. 125; GüNTERT, “Arte y furor”, p. 673; ENDRESS, Heinz-Peter, ““... una breve plática de arenga les quiero hacer.' Discursos y retórica en La Numancia”, Volver a Cervantes. Actas del IV Congreso Internacional de la Asociación de Cervantistas, Lepanto, 1-8 de octubre de 2000, ed. Antonio Bernat Vistarini, II. Palma, Universitat de les Illes Baleares, 2000, p. 943.

41. Cervantes, El cerco de Numancia, 2.569-70.

42. Ibid., 2.713-16. 
Sin embargo, la respuesta furiosa de Marandro y su insistencia en que el amor no le impide cumplir con sus deberes de ciudadano, hacen muy clara la diferencia entre las dos situaciones. Su pregunta indignada: “¿Hizo el amor, por ventura, a ningún pecho cobarde?"43 encontrará respuesta en la siguiente jornada en las palabras de Leonicio, quien tendrá que admitir que "se nos muestra claro / que no hay cobarde enamorado pecho" 44 . En pocas palabras, es obvio que se trata de un amor bien diferente del que corroe las tropas ro$\operatorname{manas}^{45}$.

Dada su natural inclinación a la acción, los numantinos buscan rápidamente una solución a su inmovilidad: proponer un duelo singular, que decidirá el desenlace de la guerra. Así pues, tal y como se puede esperar, la tercera jornada empieza con la iniciativa de los numantinos que lanzan un reto al general romano. Escipión rechaza el reto sabiendo muy bien que la inacción hará mucho más daño a los numantinos. Sin embargo, es importante notar que a partir de ahora (y hasta el final del drama), el ejército romano también se encuentra paralizado, puesto que después de haber hecho el foso, no tiene nada que hacer, salvo esperar la rendición de la ciudad rebelde ${ }^{46}$. Mientras tanto, los hombres de Numancia piensan en la última posibilidad de escapar de la inmovilidad pero su decisión de salir a pelear hasta la muerte es vetada por las mujeres.

Creo que éste es el momento crucial de la obra. Por primera vez tenemos a los dos bandos sin poder hacer nada y me parece muy significativo el hecho de que la resolución de esta tensión provenga precisamente de las mujeres numantinas. Hemos visto que, según la lógica interna de la obra, la acción parece equivaler al triunfo. Desde este punto de vista, el desenlace de la guerra depende de quién pasará a la acción primero en la cuarta jornada. Como acabo de señalar, las mujeres impiden que los numantinos salgan a pelear y, por lo tanto, parece que les quitan la oportunidad de actuar. Sin embargo, la decisión de los hombres implica la acción por parte de los dos bandos (los romanos lucharían igual que los rebeldes), mientras que, dentro de la dinámica establecida por Escipión desde el principio de la obra, lo que importa en este momen-

43. Ibid., 2.723-24.

44. Ibid., 3.1575-76.

45. CASALDUERO contrapone el amor lascivo de los romanos al amor honesto de los numantinos, Sentido y forma, p. 282. De un modo parecido, ZiMIC afirma que "los soldados romanos se han entregado, por lujuria, a las meretrices que les corrompen el cuerpo y el espíritu, mientras que Marandro y los numantinos - aman con pureza de ánimo que los inspira y fortalece para la noble acción bélica en defensa de sus hogares. Por su amor a Lira, Marandro es soldado aun más puntual, valiente y dispuesto al sacrificio", El teatro de Cervantes, pp. 71-72. Véase también ARMSTRONG-Roche, "Imperial Theater of War", p. 193. Aunque Gaos, Cervantes, p. 145, refuta esta interpretación y afirma que el objetivo de Cervantes es exaltar el amor en general, creo que la diferencia establecida entre los dos bandos es evidente y se debe, ante todo, a la función de los personajes femeninos numantinos, que discutiré en los próximos apartados.

46. Desde esta perspectiva se entiende mejor la falta de acción en el sentido tradicional, señalada por Emilie BERGMANN, que determina "the static, symbolic, and slow-moving quality of the play", "The Epic Vision of Cervantes's Numancia", Theatre Journal, 36.1, 1984, p. 93. 
to es inclinar la balanza, es decir, actuar sin dejar de intervenir al enemigo. Y es exactamente lo que va a provocar el veto de las mujeres: los numantinos deciden recurrir a la única acción posible en esta situación, la autodestrucción. De ese modo, Escipión se convierte en un burlador burlado, puesto que una actuación inhabitual por parte de su enemigo lo deja incapacitado y asegura su derrota.

Otra consecuencia importante de la intervención femenina en el discurso masculino de la Numancia es la ruptura de un paralelo que el dramaturgo parece trazar entre los romanos y los numantinos ${ }^{47}$. En efecto, desde el principio del drama existe una constante preocupación, tanto por parte de Escipión como de los numantinos, por demostrar su valor y superioridad al enemigo. De ese modo, la ciudad y el campamento romano se convierten en dos escenarios, cuyos actores son al mismo espectadores que vigilan y evalúan la representación de los otros ${ }^{48}$. Esta conciencia de estar constantemente observados, que afectará las decisiones de los dos bandos a lo largo de la obra, se vislumbra ya en el discurso inicial de Escipión: "D'esta ciudad los muros son testigos, / que aun hoy está cual bien fundada roca, / de vuestras perezosas fuerzas vanas" 49 . Por consiguiente, la reforma impuesta por el general forma parte

47. Las similitudes entre los dos pueblos en el drama de Cervantes han sido puestas de relieve por varios investigadores. El motivo más discutido son las mutuas acusaciones de soberbia que constituyen una constante desde los primeros versos hasta el final. Por ejemplo, DE ARMAS rectifica la tesis de Jane TAR, "Hamartia in Cervantes' La Numancia", Aleph, 5, 1990, pp. 22-28, sobre la doble hamartia en la Numancia, al señalar que tanto Escipión como los numantinos manifiestan soberbia excesiva (la hybris), basada en dos virtudes épicas, sapientia y fortitudo respectivamente, "Achilles and Odysseus", pp. 362-69. Francisco J. MARTín recoge esta idea pero distingue entre la hybris negativa de los romanos y la positiva de los numantinos: "La que ha salvado a Numancia ha sido precisamente esa soberbia, esa 'virtud heroica', esa hybris positiva, que decimos, la arrogancia innata en Bariato en la cual ha encontrado la voluntad, la fuerza y el valor de despreciar las atractivas promesas del general romano, y de precipitarse de la torre", "El desdoblamiento de la hamartia en La Numancia", Bulletin of the Comediantes, 48.1, 1996, p. 22. MAGLIONE, sin embargo, rechaza la división de la arrogancia en positiva y negativa y la considera como un fallo, junto con el deseo de la venganza, que aproxima y, en última instancia, perjudica a los dos bandos: "In their mutual arrogance and animosity toward each other, both parties aim at negating the other's power and increasing their own", "Amity and Enmity", p. 185. Por otro lado, Teresa HERRAIZ DE TRESCA contrapone la soberbia de Escipión a la sumisión al valor más alto y apertura a lo divino de los numantinos, "Previsión e interpretación del futuro en La Numancia de Cervantes", Para leer a Cervantes. Estudios de literatura española Siglo de Oro, ed. A. Parodi y J. D. Vila, I. Buenos Aires, Eudeba, Universidad de Buenos Aires, 1999, p. 245. Aparte del motivo de la arrogancia, se han señalado semejanzas entre los romanos y los numantinos desde el punto de vista de la estructura (FrIEDMan, The Unifying Concept, p. 58; "Poetic Discourse and Performance Text: Toward a Semiotics of the Comedia", Approaches To Teaching Spanish Golden Age Drama, ed. Everett W. Hesse, York, SC, Spanish Literature Publications Company, 1989, p. 63), de la imaginería (LARSEN, "Observations on the Animals", p. 71; STIEGLER, "The Coming of the New Jerusalem", p. 571) y del motivo del sacrificio (GRAF, "Valladolid dellenda est", p. 274; PETRO, Antonia, "El fallido ritual sacrificial en La Numancia de Cervantes", Bulletin of Spanish Studies, 82.6, 2005, pp. 763-66).

48. Christina Karageorgou-BAStea analiza esta doble función de actor/espectador pero la circunscribe a los personajes numantinos de la obra, "Del coro al héroe en la Numancia Cervantina", Theatralia, 5, 2003, pp. 53-65.

49. Cervantes, El cerco de Numancia, 1.77-79. CANAVAgGio señala que uno de los objetivos de la arenga de Escipión es precisamente destruir la imagen de los romanos como débiles y de los numantinos como invencibles, Cervantès dramaturge, p. 354. 
de la representación que se va a realizar para los numantinos: "Estoy con todo esto tan seguro / de que al fin mostraréis que sois romanos" "50. Creo además que ésta es una de las posibles explicaciones para su decisión de declinar la propuesta de paz por parte de los numantinos:

¡Tarde de arrepentidos dais la muestra!
Poco vuestra amistad me satisface.
De nuevo ejercitad la fuerte diestra,
que quiero ver lo que la mía hace.
Quizá que ha puesto en ella la ventura
la gloria nuestra y vuestra sepultura ${ }^{51}$.

Es decir, parece que Escipión quiere continuar la guerra para ver y, por extensión lógica, para dejar ver a sus enemigos las capacidades de su 'fuerte diestra' ${ }^{\prime 2}$. Es como lo entienden los embajadores numantinos que, aunque indignados por la respuesta del romano, acaban por aceptar su desafío: "entonces verás lo que podremos / cuando nos muestres tú lo que pudieres"53. A partir de este momento, los rebeldes comparten con sus enemigos la obsesión por demostrar su supremacía mediante una especie de performance del valor. Al encontrarse incapacitados para actuar en la segunda jornada, se esfuerzan por encontrar un modo de continuar su representación: "hagamos todo cuanto hacer podemos / para mostrar los ánimos osados. / A nuestros enemigos convidemos / a singular batalla ${ }^{54}$. Como ya hemos visto, cuando esta opción les es negada, deciden salir todos a pelear para que "esta noche se muestre el ardimiento / del numantino acelerado pecho / y póngase por obra nuestro intento" 55 . Finalmente, al optar por el suicidio colectivo, los rebeldes también toman en cuenta la presencia de un público:

Sólo se ha de mirar que el enemigo no alcance de nosotros triunfo o gloria; antes ha de servir él de testigo que apruebe y determine la historia ${ }^{56}$.

50. Cervantes, El cerco de Numancia, 1.161-62.

51. Ibid., 1.267-72.

52. La aparente falta de lógica detrás de la decisión del general ha sido subrayada por GAOs: “¿Por qué Escipión se niega a aceptar la sumisión de Numancia, dispuesta a ponerse 'a cualquier partido', esto es, a rendirse sin condiciones? No parece que la justificación - 'A desvergüenza de tan largos años / es poca recompensa pedir paces' - sea el verdadero motivo por el que decide continuar las hostilidades", Cervantes, pp. 139-40. Según Maglione, Escipión rechaza la embajada de los numantinos porque no busca la paz, sino la venganza por el ultraje que han causado los rebeldes a la reputación de Roma, "Amity and Enmity", p. 182. En este sentido es lógico que tal venganza se conciba como una demostración pública y ejemplar de la superioridad militar de las tropas imperiales.

53. Cervantes, El cerco de Numancia, 1.293-94 (el subrayado es mío).

54. Ibid., 2.571-74 (el subrayado es mío).

55. Ibid., 3.1242-44 (el subrayado es mío).

56. Ibid., 3.1418-21. Como indica CANAVAGgio, “ils n'entendent pas moins démontrer, par leur sacrifice, que leur anéantissement ne sera qu'une péripétie; c'est ce que confirme, au demeurant, le discours final de la Renommée", Cervantès dramaturge, p. 354. 
No es sorprendente, por lo tanto, que el caos que invade la ciudad como resultado de su decisión sea denominado por los mismos numantinos como "triste espectáculo" 57 . Desde esta perspectiva es interesante recordar cómo acaba la vida del líder de los rebeldes. Después de haber matado a su mujer y sus hijos, Teógenes decide morir honrosamente al entrar en combate con otro numantino. Para ello literalmente asume el papel del enemigo: "Valientes numantinos, haced cuenta / que yo soy algún pérfido romano, / y vengad en mi pecho vuestra afrenta" 58 . Como ha señalado Hermenegildo, se trata de una teatralización del combate que además se da en un lugar en que la lucha podrá realizarse de forma más espectacular, la plaza de la ciudad ${ }^{59}$. Para este crítico, el recurso al artificio del 'teatro en el teatro' marca la diferencia entre la muerte de Teógenes y la de los otros numantinos ${ }^{60}$. Sin embargo, como hemos podido observar, la teatralidad de las últimas acciones del jefe de los numantinos concuerda perfectamente con el comportamiento de sus compatriotas en su intento de demostrar públicamente su valor ${ }^{61}$. Además, su espectáculo fracasado resulta análogo al fiasco final de Escipión, como veremos en seguida.

El general romano elude el enfrentamiento directo con los numantinos para asegurar el éxito de la empresa ${ }^{62}$. Al mismo tiempo, se entiende que la nueva táctica puede oscurecer su imagen de militar valeroso, puesto que "era mengua del romano brío / no vencellos con modos más usados"63. Por lo tanto, necesita un acto espectacular que concluya su misión y pruebe que el fin justifica los medios: la rendición de la ciudad, conseguida sin haber derramado ni una gota de sangre romana. De ahí su gran preocupación por conseguir al menos un superviviente: "Con uno solo que quedase vivo, / no se me negaría el triunfo en Roma"64. Es decir, la exhibición pública de un preso numantino en Roma le permitiría a Escipión reclamar la victoria y la honra, algo que queda imposibilitado por la caída de Bariato. Algo parecido sucede en el caso de Teógenes. A pesar de que la idea del suicidio colectivo provenga del jefe numantino, él mismo al principio evade la autodestrucción, que no le parece lo suficientemente honrosa, y elige la alternativa de morir luchando. Es decir,

57. Cervantes, El cerco de Numancia, 3.1664.

58. Ibid., 4.2148-50.

59. La "Numancia”, p. 90.

60. HermenEgildo, Alfredo, "Mirar en cadena: artificios de la metateatralidad cervantina", Cervantes y la puesta en escena de la sociedad de su tiempo (Actas del Coloquio de Montreal, 1997), coord. C. Poupeney Hart, A. Hermenegildo y C. Oliva, Murcia, Universidad de Murcia, 1999, p. 84.

61. VIVAR nota que "la teatralidad de la muerte, llena de palabras y acciones simbólicas, se presenta en los casos ejemplares de Leonicio y Manandro, Teógenes y Bariato que siguen el modelo de la muerte de Jesucristo y reflejan el sacrificio colectivo de los ciudadanos numantinos", "El ideal pro patria mori", p. 22.

62. Como él mismo admite al final, la destreza en armas de los rebeldes le forzó a "encerrallos cual fieras indomables / y triunfar de ellos con industria y maña, / pues era con las fuerzas imposible", Cervantes, El cerco de Numancia, 4.2254-56.

63. Ibid., 3.1123-24.

64. Ibid., 4.2244-45. 
lo que le preocupa, igual que a Escipión, es su imagen pública, por lo cual continúa persiguiendo el mismo objetivo de hacer una demostración de su valor, al que aspiraban todos los numantinos antes de la intervención de sus mujeres. Más tarde nos enteramos de que el intento del caudillo ha fallado y se ha tenido que arrojar a las llamas; así, pues, su representación ha quedado inconclusa e inútil. Según Hermenegildo, "el método de Teógenes, que de modo tan teatral evita el suicidio directo y, en realidad, más honroso, resulta ser un proceso ineficaz, puesto que deja inacabada la operación. Teógenes quiere morir honrosamente, y no logra, por medio de una puesta en escena bien marcada en el texto, asegurar la realización de su propio sacrificio"65. De ese modo, el fracaso de los dos caudillos se puede considerar como resultado directo de sus esfuerzos por mantener su reputación mediante algún acto espectacular. En pocas palabras, la preocupación común por hacer una mejor representación de su competencia militar hasta cierto punto equipara a los numantinos con sus enemigos. Cabe notar que no se trata de una equiparación ventajosa, puesto que todos los hombres, como hemos visto, acaban prestando más atención a las apariencias que a la realidad ${ }^{66}$. Es precisamente donde la intervención de las mujeres marca la diferencia entre los dos bandos, puesto que la elección del suicidio colectivo no se basa tanto en su aspecto teatral como en el resultado final, que es morir sin dejar nada al enemigo. En otras palabras, gracias a las mujeres, se elige una nueva meta, que resulta básicamente opuesta a la de la salida estorbada de los hombres, donde lo esencial era mostrar "el ardimiento del numantino acelerado pecho", mientras que el desenlace de la empresa se veía como un efecto secundario ${ }^{67}$. Así pues, si los hombres se dejan cegar por sus impulsos en una absurda obsesión por el aspecto más superficial de la acción (la representación / las apariencias), las mujeres consiguen redirigirlos hacia el buen camino al ponderar racionalmente las implicaciones y las consecuencias de sus decisiones ${ }^{68}$.

Por consiguiente, se puede concluir que, en contraste con lo que pasa en el campo romano, las mujeres numantinas estimulan a sus hombres a la única acción correcta en un instante decisivo de la guerra o, en otras palabras, les sir-

65. "Mirar en cadena", p. 87.

66. Sobre el recurso al metateatro en relación con la oposición realidad / apariencias en la dramaturgia de Cervantes, véase CANAVAGGIO, Jean, "Variations cervantines sur le thème du théâtre au théâtre", Revue des Sciences Humaines, 145, 1972, pp. 63-64, así como ArbolEDA, Carlos Arturo, Teoría y formas del metateatro en Cervantes, Salamanca, Universidad de Salamanca, 1991.

67. El mismo Teógenes admite que "sólo sirve esta hazaña / de que a nuestro morir se mude el modo", CERVANTES, El cerco de Numancia, 3.1248-49 (el subrayado es mío).

68. Parece que esta subversión de uno de los antiguos estereotipos, que asocia lo masculino con la razón y lo femenino con lo irracional, no es peculiar de El cerco de Numancia. Louis ComBET señala que en toda la obra de Cervantes la superioridad racional, por lo general, es característica de los personajes femeninos: "L'analyse des différentes intrigues du corpus montre à l'évidence que cette supériorité discursive attribués à l'homme ne se manifeste pas davantage lorsque le temps de la réflexion lui est donné. Même après 'mûre délibération', l'avis de la femme l'emporte le plus souvent en sagesse et en intelligence", Cervantès ou les incertitudes du désir: une approche psychostructurale de l'ouvre de Cervantès, Lyon, Presses Universitaires de Lyon, 1980, p. 47. 
ven de inspiración ${ }^{69}$. Este papel de inspiradora se pone en evidencia por el único personaje femenino que tiene nombre: la enamorada de Marandro, Lira $^{70}$. Ya hemos visto que el amor de Lira de ningún modo acobarda a su amado, sino que todo lo contrario. La última jornada empieza con una acción por parte de los numantinos que anticipa su triunfo, puesto que es la primera acción realizada después del período de inmovilidad en los dos campos. Leonicio y Marandro salen de la ciudad y alborotan las tropas romanas para conseguir un pedazo de pan para Lira, quien se está muriendo de hambre. Es, por supuesto, un gesto de autodestrucción (los dos mueren) pero, al mismo tiempo, es una muerte que da vida, igual que el suicidio colectivo dará vida a la fama eterna de Numancia. Lo interesante aquí es el valor y la nobleza de espíritu de la doncella, quien se opone a la decisión de su amado:

que más importa tu vida que la mía en la ciudad.

Tú podrás bien defendella de la enemiga asechanza, que no la flaca pujanza desta tan triste doncella ${ }^{71}$.

Su abnegación a favor del bien colectivo la convierte en una figura más que digna de la hazaña que le dedica Marandro. Lo mismo se puede decir de las otras mujeres numantinas, incluyendo a la mujer de Teógenes, la cual expresa un valor y determinación envidiables incluso quizá por su propio marido, quien, como hemos visto, dilata el momento de su propia muerte.

En resumen, si volvemos a la asociación que se establece entre las numantinas y la tierra, podemos ver que el ataque al cuerpo de Numancia / España es resistido y contrarrestado por la actuación de los personajes femeninos, que en su función de inspiradoras de los hombres, hacen todo lo posible para asegurar la derrota del enemigo. Al mismo tiempo, al tomar en cuenta el hecho de que los hombres numantinos también se identifican con España, nos encontramos con una situación más bien curiosa en lo que se refiere al aparentemente doble mensaje de la obra. En efecto, el análisis realizado en este trabajo nos lleva a la conclusión de que la ambigüedad ideológica del drama de Cervantes proviene del desdoblamiento de la imagen de España en imperio y la tierra. Por un lado, los paralelos que se establecen entre los hombres numantinos y los romanos, así como las predicciones de los personajes alegóri-

69. Sobre la importancia de la intervención de las mujeres numantinas en la tercera jornada escribe CANAVAGGIO: "A la différence des épisodes spectaculaires que sont le sacrifice aux dieux ou le suicide de Marquino, cette intervention constitue, en plein sens du terme, une péripétie: entendons par là un reversement de situation par lequel Numance se refuse à subir le destin qui lui a été réservé, pour l'assumer librement à travers le sacrifice de ses défenseurs et, par là, le choisir', Cervantès dramaturge, p. 255. Véase también MAESTRO, La escena imaginaria, p. 183-184.

70. La elección del nombre Lira, una de las nueve Musas, por supuesto, no es casual.

71. CERVANTES, El cerco de Numancia, 3.1532-37. 
cos, vinculan la antigua ciudad con el imperio español del siglo XVI. Por otro lado, la asociación de las mujeres numantinas con el cuerpo de España hacen de Numancia un símbolo de la tierra española en general. Desde esta perspectiva, el mensaje de la obra ya no resulta tan ambiguo. El imperio no tiene pertenencia nacional, no importa si es romano, español, británico, etc. Su política es universal y es siempre la misma: se basa en el militarismo, la opresión y la ostentación del poder (de ahí la importancia de los paralelos que establece el drama entre los dos bandos). El territorio común, al contrario, constituye un factor clave en la formación de la mayoría de las identidades étnicas y nacionales. Basta recordar que la presentación de los numantinos como antecesores de los españoles sólo es posible gracias a una coincidencia geográfica. Puesto que el imperio no puede ser asociado con una sola comunidad, no puede ni representar ni inspirar a las personas que forman parte de tal comunidad. Por consiguiente, los romanos de la obra no tienen nada que los suscite a hacer guerra, salvo el miedo ante su riguroso jefe, mientras que los numantinos son inspirados y guiados por sus mujeres que funcionan como una encarnación de su tierra. Así pues, una visión crítica del imperialismo español no contradice la lógica interna de la obra. Los imperios suben y caen y la derrota de Roma prometida por Duero contiene a la vez un presagio de la caída del imperio español, puesto que, igual que los romanos en el drama, los españoles de la época de Cervantes, que luchan en territorios ajenos, no tienen la misma inspiración que tenían sus heroicos antecesores: la tierra patria.

\section{Resumen}

El objetivo de esta investigación es examinar la visión del imperio que nos ofrece El cerco de Numancia de Cervantes mediante un estudio de la interacción del plano 'real' de la obra, el de los numantinos y los romanos, con el plano simbólico de los personajes alegóricos. Por un lado, se pueden observar ciertos paralelos entre los romanos y los hombres numantinos que el dramaturgo establece recurriendo al motivo del "teatro dentro del teatro". Por otro lado, la asociación que se produce entre las mujeres numantinas y la tierra española contribuye a romper estos paralelos y nos presenta con una posible alternativa al imperialismo militante. Al centrarse en la oposición acción / inacción, que subyace la tragedia, así como en la función de los personajes femeninos, este trabajo pretende esbozar la idea nacional que transmite la obra cervantina.

Palabras clave: alegoría, imperio, idea nacional, relaciones entre los géneros, metateatro, acción / inacción, tierra patria.

\footnotetext{
Abstract

This paper examines the vision of empire offered by Cervantes in his tragedy El cerco de Numancia. It explores the interaction between the two worlds present in the drama: the "real" world of the Numantians and the Romans, and the "symbolic" world of allegorical characters. On the one hand, we can observe certain parallels between the Romans and the Numantian men, which are reinforced by the use of the "theater within theater" motif. On
} 
the other hand, the association between Numantian women and the Spanish soil shatters these parallels and presents a possible alternative to militant imperialism. By focusing on the opposition action / inaction, which underlies the tragedy, together with the function of female characters, this analysis intends to outline the national ideal transmitted by Cervantes' work.

Key words: allegory, empire, national ideal, gender relations, metatheatre, action / inaction, native soil. 